\title{
CHARACTERIZATION OF HEART RATE ELECTRODES USING ELECTROCHEMICAL IMPEDANCE SPECTROSCOPY
}

Jennifer Deignan ${ }^{1}$, Michael McBrearty ${ }^{2}$, Javier Monedero ${ }^{3}$, Shirley Coyle ${ }^{1}$, Donal O'Gorman ${ }^{3}$, Dermot Diamond ${ }^{1}$ ${ }^{1}$ Insight Centre for Data Analytics, National Centre for Sensor Research, Dublin City University, Ireland.

2adidas Wearable Sports Electronics, Chadds Ford, Pennsylvania, United States.

${ }^{3}$ School of Health and Human Performance, Dublin City University, Ireland.

\section{Introduction}

Wearable monitoring systems have flooded the health and sports industry in recent years. With a continued focus on comfort and cross platform use, it is important that accuracy also remains a priority. Standard disposable hospital monitoring electrodes are accurate in large part due to the reduction-oxidation reaction of $\mathrm{Ag} / \mathrm{AgCl}$. The following work presents a testing method to compare future generations of heart rate monitoring devices to the current standard of disposable $\mathrm{Ag} / \mathrm{AgCl}$ electrodes using electrochemical impedance spectroscopy.

Background
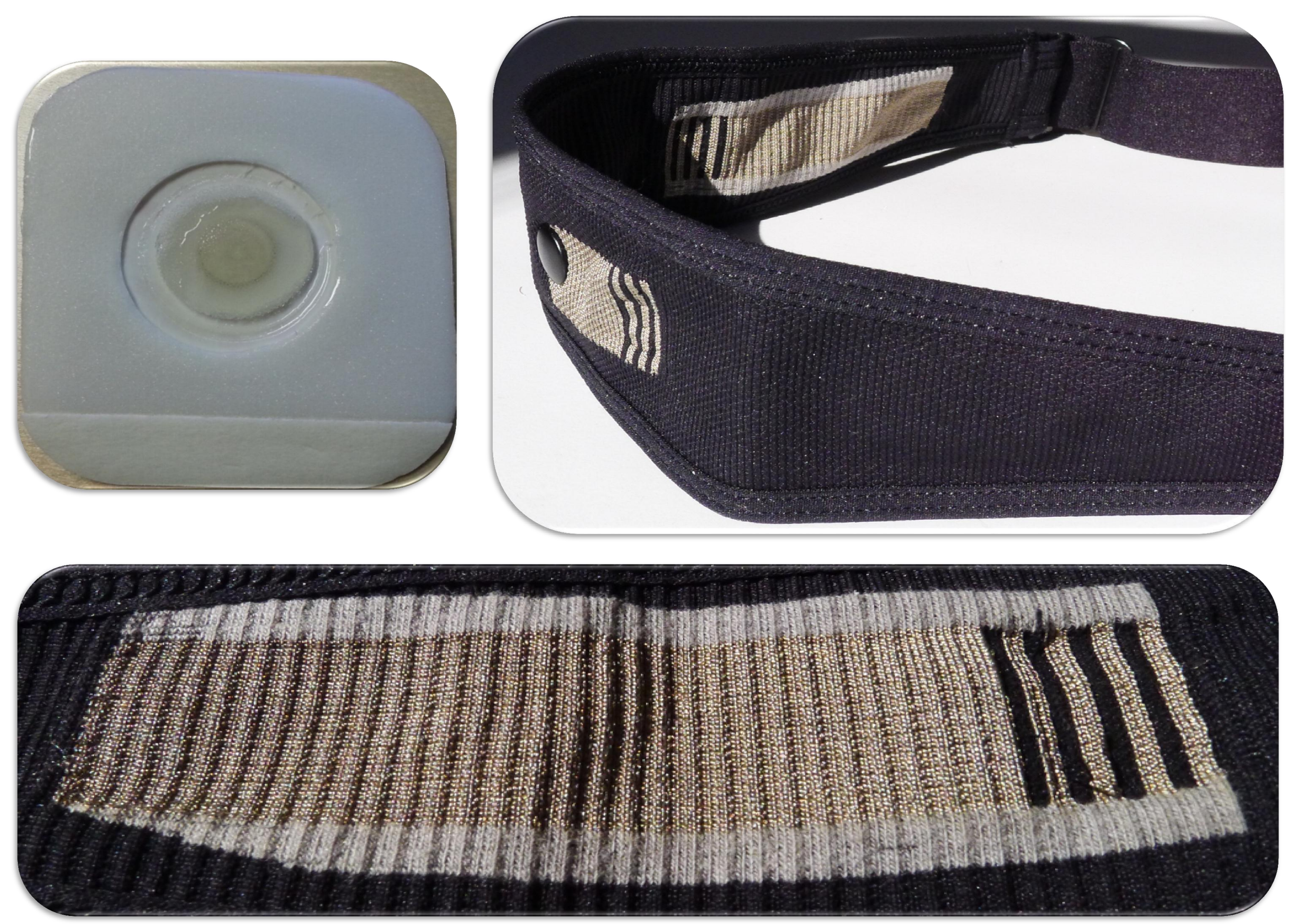

Standard $\mathrm{Ag} / \mathrm{AgCl}$ disposable monitoring electrodes rely on the wellknown $\mathrm{AgCl}+\mathrm{e}-\leftrightarrow \mathrm{Ag}+\mathrm{Cl}$ - reduction-oxidation reaction to produce clear, reliable electrocardiogram (ECG) signals for inpatient monitoring. However, these electrodes are not suitable for athletic monitoring for many reasons, most notably the discomfort of the user and the preparation needed before application. However, silver coated fabrics could overcome the comfort issue, and provide the solution for continuous, real-time motion and non-motion measurements in daily life.

\section{Impedance Measurements}
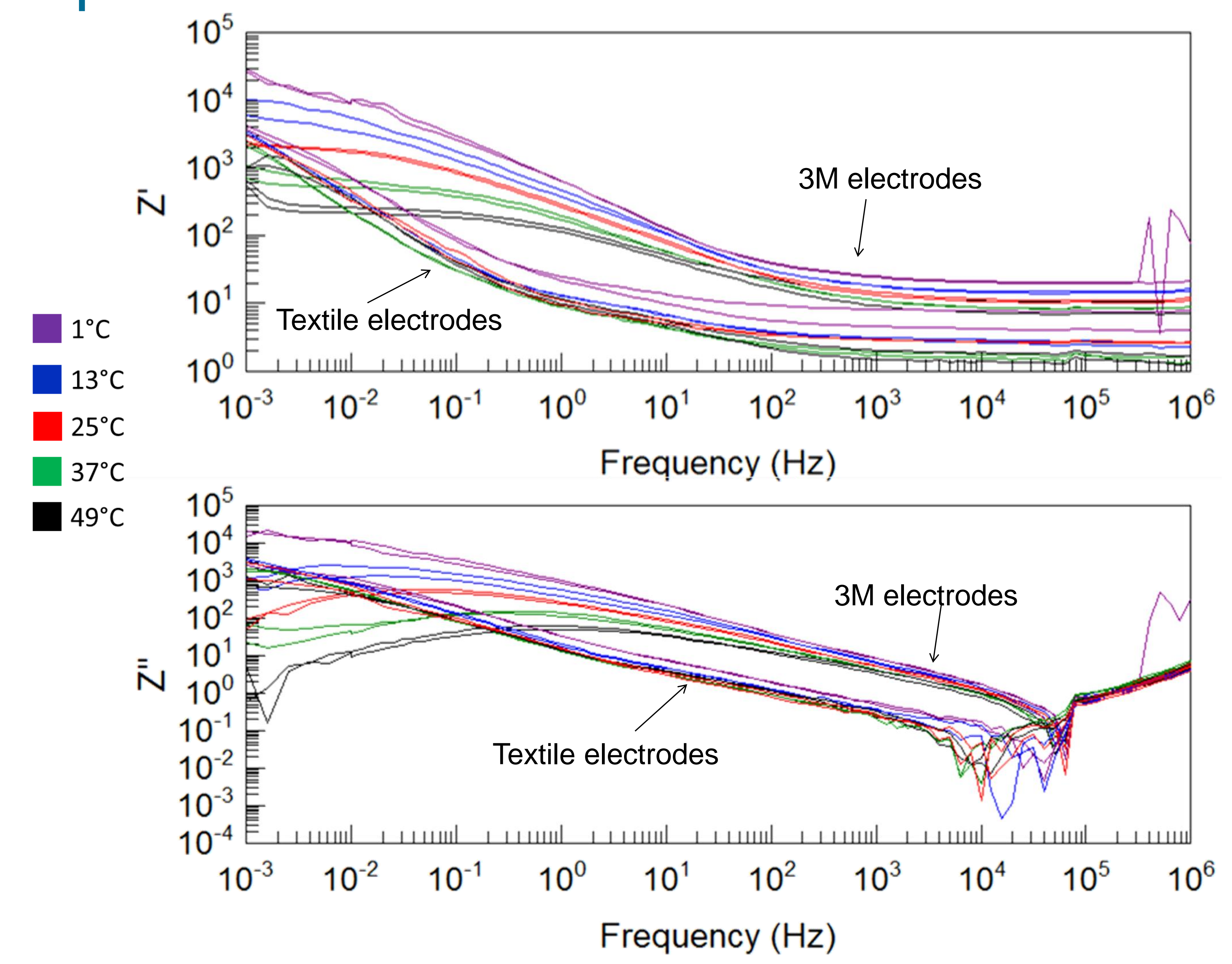

Impedance measurements of adidas textile strap electrodes were compared to $3 \mathrm{M}$ Red Dot 2230 diaphoretic monitoring electrodes measurements. An impedance sweep from $1 \mathrm{MHz}$ to $1 \mathrm{mHz}$ was conducted on the samples at $1^{\circ} \mathrm{C}, 13^{\circ} \mathrm{C}, 25^{\circ} \mathrm{C}, 37^{\circ} \mathrm{C}$ and $49^{\circ} \mathrm{C}$. The data for each temperature was then modeled to the appropriate equivalent circuit.

\section{Blocking and Non-Blocking Electrodes}

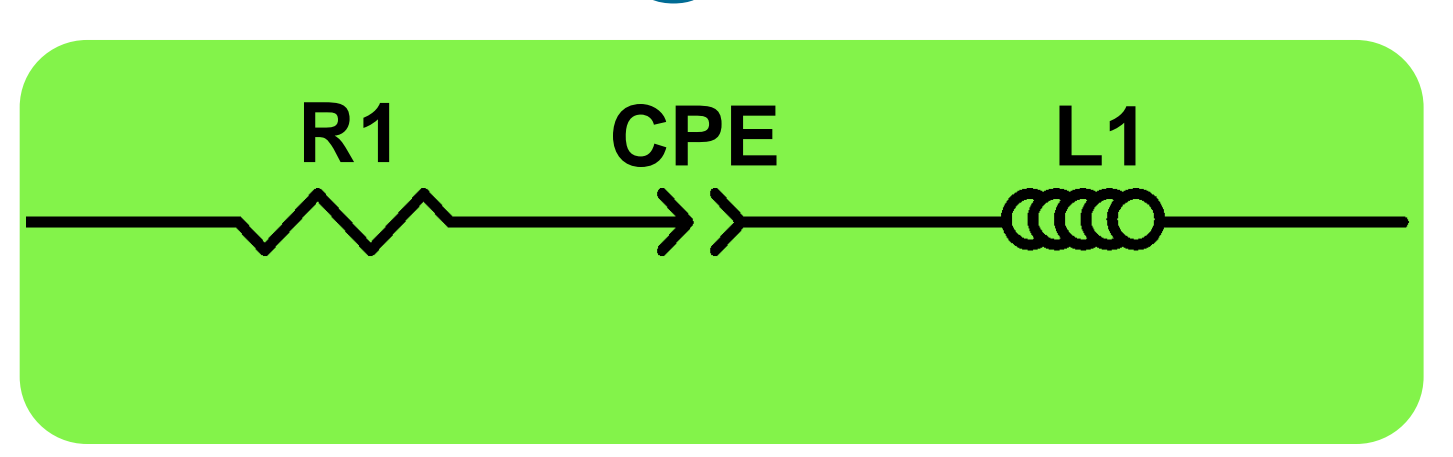

R1

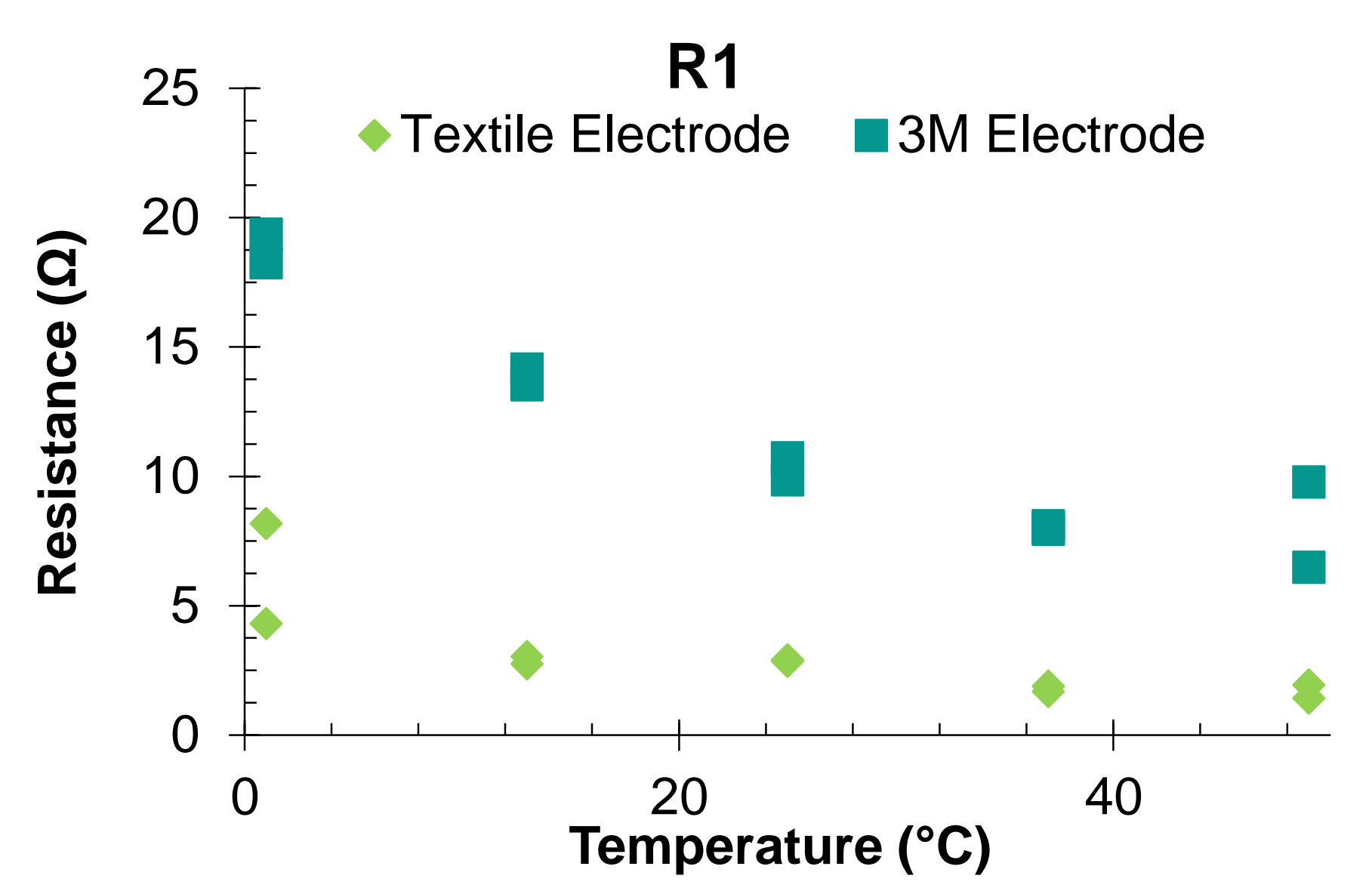

CPE ( $\alpha)$

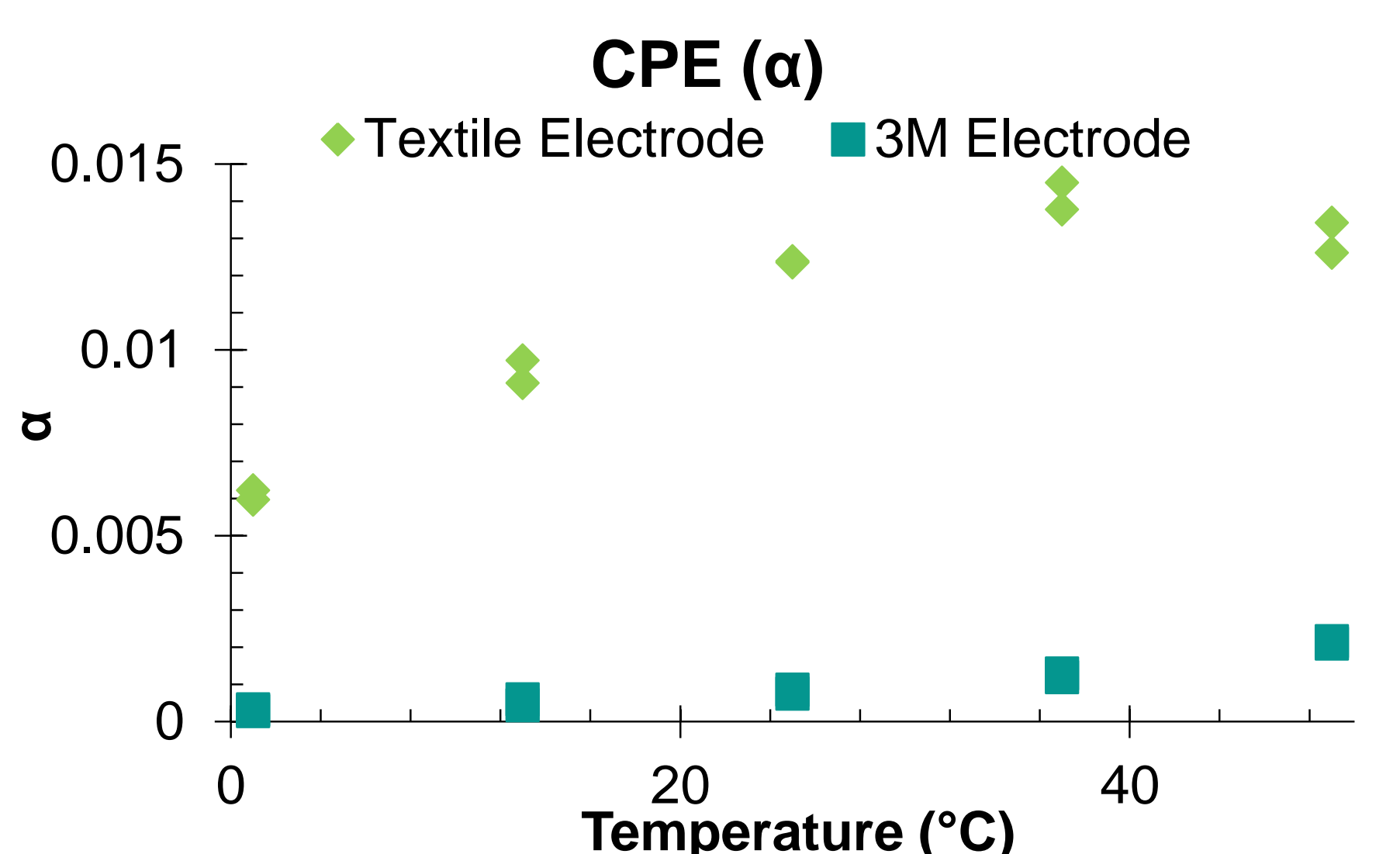

R2 strongly influences impedance at low frequencies suggesting that this parameter determines the effectiveness of the electrode as a heart rate monitor. The CPE data supports this interpretation, illustrating the differences in capacitive and resistive tendencies of the textile and $3 \mathrm{M}$ electrodes, respectively.

\section{On-body Testing}

Without electrode gel on textile electrode

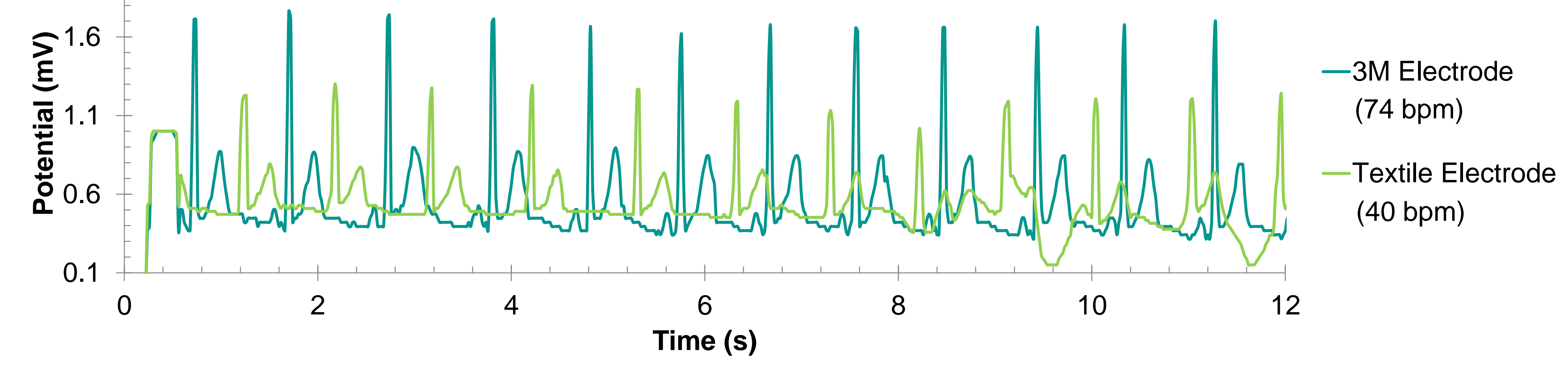

With electrode gel on textile electrode

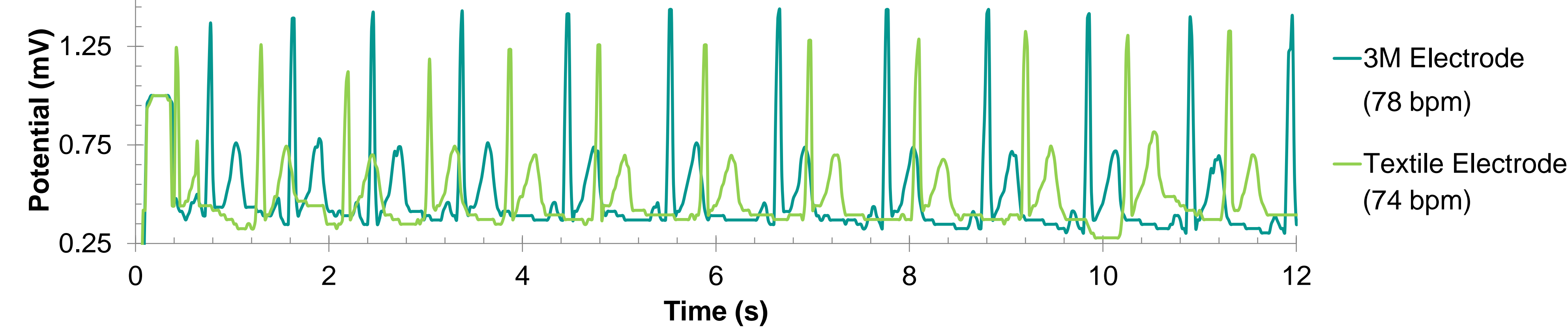

Resting ECG measurements were taken on a healthy adult male with both electrodes simultaneously. Without electrode gel, the textile electrodes showed erratic behavior, with sudden increases and decreases in heart rate that were not present with the $3 \mathrm{M}$ electrodes.

\section{Conclusions}

Wearable sensors are the key to continuous monitoring for health, sports and exercise. Heart rate monitors are essential to the realization of whole body monitoring systems. With the addition of a significant R2 component, the accuracy of textile based sensors can be dramatically improved and whole body monitoring systems could be created.

Acknowledgments

Science Foundation Ireland under the Insight initiative, grant SFI/12/RC/2289. 